\title{
INFLUENCE OF CORROSION PITTING ON ALLOY 718 FATIGUE CAPABILITY
}

\author{
Jon R. Groh* and Ron W. Duvelius* \\ *GE Aircraft Engines \\ Material and Process Engineering Department \\ Cincinnati, Ohio
}

\begin{abstract}
During the early 1990s, GEAE rotor manufacturing experienced a high frequency of pitting corrosion on as-manufactured surfaces of Alloy 718 components. Characterization of pits indicated aqueous chloride corrosion on a general front with delta platelets in relief. Attempts to reproduce this condition within the hard chrome electroplating shops were not successful. Pitting frequency was minimized with improved masking techniques but was not completely eliminated until the requirement for $\mathrm{Cr}$-plating was deleted.

Laboratory efforts to reproduce this condition yielded an electrolytic method to reliably generate pits with similar delta-rich features. Severity of pitting, frequency and size, varied with time in the electrolytic cell. Fatigue specimens of two severity levels were tested at $177^{\circ} \mathrm{C}$ showed a 3-5X debit on fatigue lives versus baseline Alloy 718 behavior. Although pitting severity was a statistically significant factor, the primary debit was the presence of a pit to initiate fatigue.
\end{abstract}

Superalloys 718.625.706 and Various Derivatives

Fdited by E. Loria

TMS (The Minerals. Metals \& Materials Society). 2001 


\section{Introduction}

The manufacture of Alloy 718 gas turbine components requires exposure of finishmachined surfaces to chemical agents that can promote chemical attack. Simon and Thoma ${ }^{1}$ reported that precipitation-hardened Superalloys, including Alloy 718, are susceptible to pitting in oxidizing chemicals. GE Aircraft Engines has experienced sporadic episodes of corrosion pitting since approximately 1974. Pits encountered in new manufacture require mechanical rework to remove within blend limits at the risk of a costly rejection as surface discontinuities were assumed to degrade material properties. In general, the cause of pitting has been reported as aqueous chloride attack; however, attempts to reproduce this condition using shop processes and chemicals were largely unsuccessful. Pits observed in components returned from field use have also been reported on occasion. Chemicals used to clean and inspect these components are typically difficult to determine from service records.

Although pitting has also been observed on the Rene' series of nickel-base alloys, the majority of incidences involve the various grades of Alloy 718 . The shear volume of 718 in GE Engines is a factor; however, it appears that alloy composition also plays a role. The presence of chromium (18 wt. \%) in conjunction with relatively low Mo (3 wt. \%) content promotes passive film formation. Local film interruption at second phase particles (carbides, nitrides, and carbonitrides, possibly delta) may provide sites for local $\operatorname{attack}^{2}$

During 1990, a particularly severe rash of pitting was encountered on critical rotating part surfaces in new parts manufactured in the Evendale, Ohio facility. Alloy 718 shafting components from GEAE's engine programs experienced rejection rates of 25 and 50\%, respectively. The primary suspect was electroplating operations performed on each component to protect critical bearing journal dimensions from wear during assembly/disassembly operations. ${ }^{3}$

Cross-sections depicted in Figure 1 illustrate part complexities requiring creativity with respect to handling, plating, and masking techniques. Changes in masking practice prior to hard Cr-plating operations minimized further pitting occurrence. Complete elimination of pitting corrosion was achieved only upon elimination of hard chromium plating as a production practice for bearing journals and replacement as a dimensional restoration practice.

This paper documents the pit characteristics, efforts to simulate the observed pitting condition on test coupons, and the impact of corrosion pitting on fatigue behavior of Alloy 718 . The primary intent was to provide data to verify GEAE lifing methodology which assumed that a pit of diameter $2 \mathrm{C}$ behaves similar to a tight, penny-shaped crack of length $2 \mathrm{C}$ by a depth of $\mathrm{C}^{4}$ Based on these data, life methods were confirmed and all pitted components were either blended to remove indications within drawing limits or scrapped. 


\section{Experimental Procedure}

A LPT shaft was rejected in visual inspection for pitting along the length of the tube (Figure 1 sketch). The largest reported pit size was $0.9 \times 0.8 \times 0.2 \mathrm{~mm}$ in depth. This part had been plated, stripped, and replated per AMS2406. Destructive analysis was conducted to characterize this condition to determine root cause and provide a basis for simulation on mechanical test bars. A total of five pits were diamond cut for metallographic preparation of an axial-radial plane for SEM-EDS. Each pit was steppolished, in kerosene, in 10-mil increments to obtain maximum dimensions and crosssections. Two additional pits were evaluated for composition via SEM/EDS in the asreceived condition. Auger microprobe analysis was performed at Perkin-Elmer Physical Electronics Laboratories. Direct Plasma Sputtering on an axis normal to the pit was followed by spectra acquisition of the freshly exposed surface. Nominal material removal rate was 30 angstroms per minute.

The LaQUE Center generated Potentiodynamic polarization curves for sixteen fluids used in part finishing. ${ }^{5}$ Basic test procedure details are described in ASTM Standard G-61 ${ }^{(5)}$. Wafers, sectioned from the subject LPT shaft, measured $15.6 \mathrm{~mm}$ diameter X $2.5 \mathrm{~mm}$ thick. Material was in the solution and aged condition in accordance with AMS5663. All testing was performed at room temperature and specimens were wet ground to 600 grit immediately prior to test.

Fatigue test specimens with a $5.1 \mathrm{~mm}$ gage diameter were machined from GFM forged Allvac 718 bar for strain-control LCF test. Several iterations to pit freshly prepared test bar surfaces were attempted before settling on a method to manufacture pits on bars for test. Optical and SEM metallography were performed for comparison to features of pits encountered on actual hardware. The selected corrosion method was $3.5 \% \mathrm{NaCl}$ in at 50 $65^{\circ} \mathrm{C}$ tap water using a platinum cathode at 3-5 volts. Masking was applied on the specimen shoulder where larger cross-section would minimize the probability of crack initiation at knife-line attack. Exposing the 718 gage anode at either four or seven minutes produced two levels of pit severity. Pitted plus baseline tests were conducted by Metcut Research test at $177^{\circ} \mathrm{C}, \mathrm{R}=0.05,20 \mathrm{cpm}$.

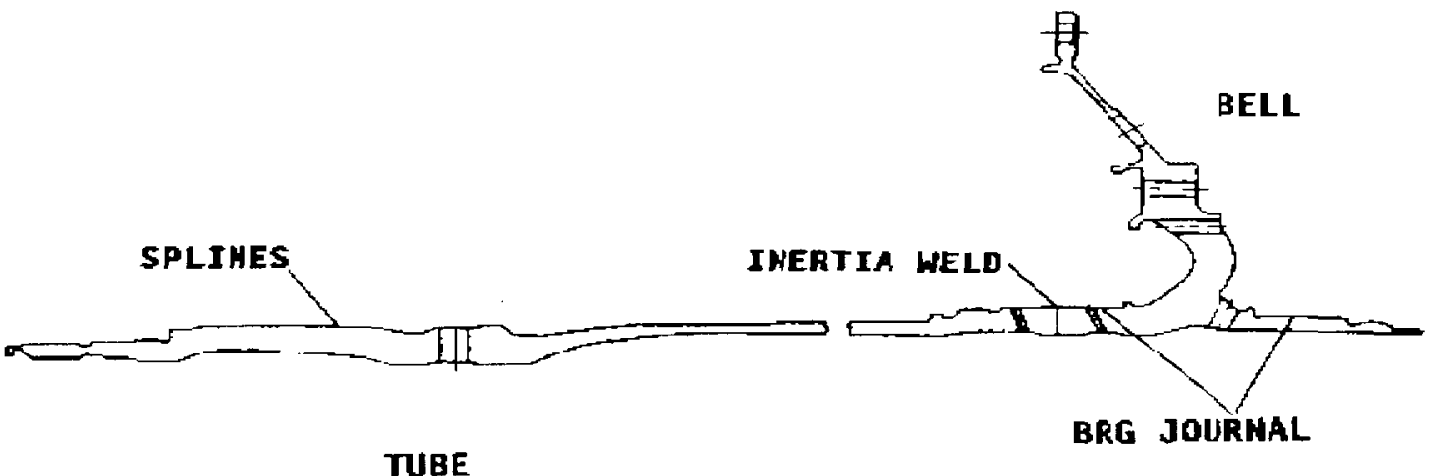

Figure 1 LPT shaft sketch showing Cr-plated bearing journal locations. Corrosion pitting was observed along the tube length as well as spline and bell areas. 


\section{Experimental Results}

\section{$\underline{\text { LPT Shaft Corrosion Pit Features }}$}

General features of OD tube pits from a LPT shaft are provided in Figure 2. The backscatter electron image of additional pit cross-sections shows delta platelets in relief, undercut of the part surface, and corrosion products collected within the pit. These photos demonstrate that visual inspection as a non-destructive means of determining pit dimensions can be misleading. Some evidence of selective intergranular attack is evident at the corrosion front, but the balance of the structure is also consumed within about one grain diameter. EDS of the bulk corrosion product confirms high niobium, characteristic of delta platelets, provides concentrations of calcium, chlorine, potassium, and silicon and a slightly reduced iron content.

Auger data showed chlorine, carbon, oxygen, and iron enrichment at the pit surface with a switch iron-rich to nickel-rich oxide at approximately $2 \mu \mathrm{m}$ from the original part surface with a coincident increase in chlorine. These results indicate that $\mathrm{Cl}$ was active in pit initiation and propagation and that eventual overlayment of nickel with iron oxide occurs in latter stages of pit growth.

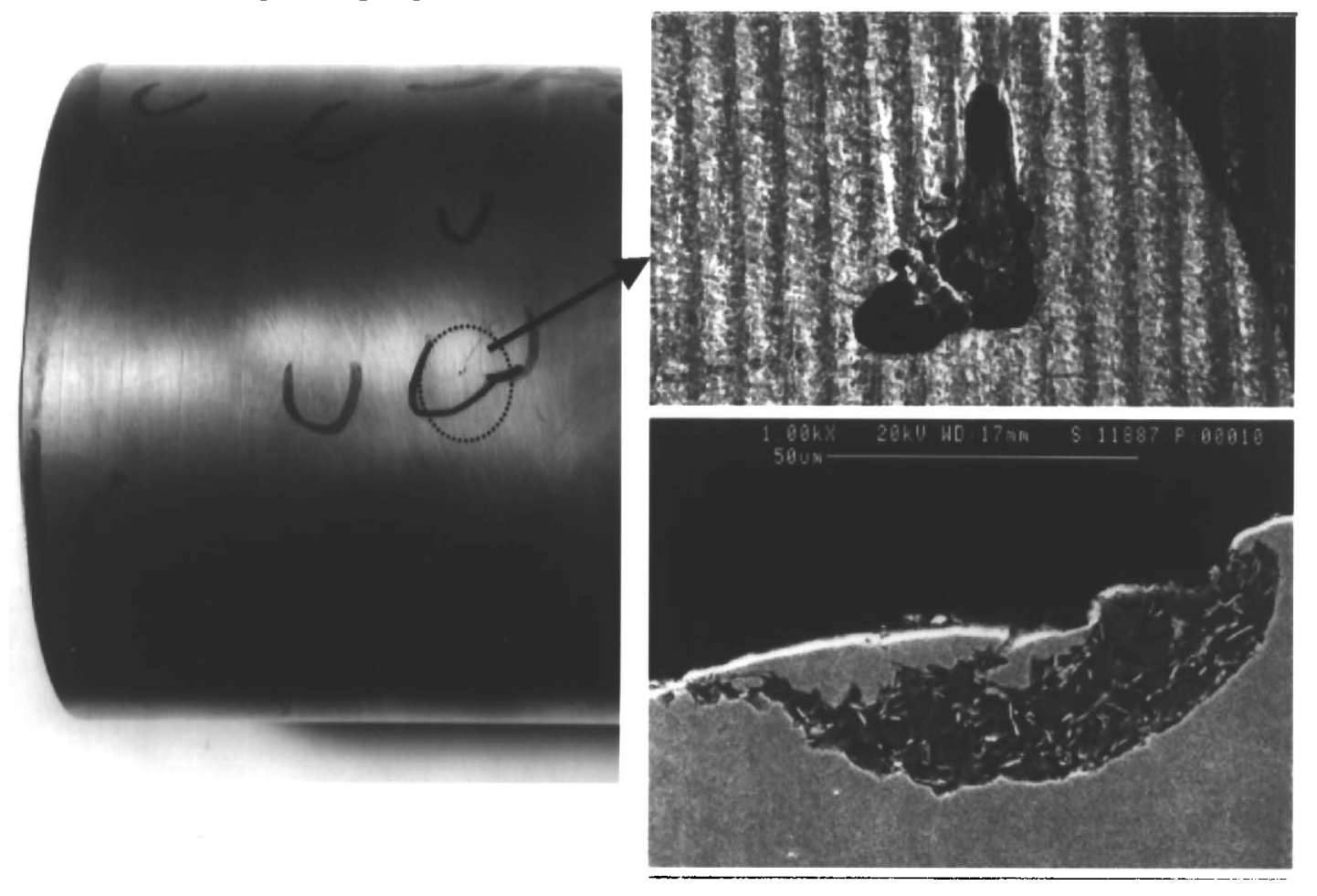

Figure 2 Pitting observed in new manufacture of shaft tube, nominal 5" OD. Backscatter electron image of pit cross-section shows that delta phase remains intact during pit formation and propagation. 
Alloy 718 pitting was observed on samples that produce open hysteresis during forward and reverse polarization scans typical of Figure $3 .^{6}$ Data were of use in identifying processing fluids that cause corrosion. The curve and sample presented represent Alloy 718 response to shop fluids that contain GE tap water (i.e., FPI emulsifier, steam cleaning agents). Alloy response was key to identification of a method to create pitting on test bar surfaces.
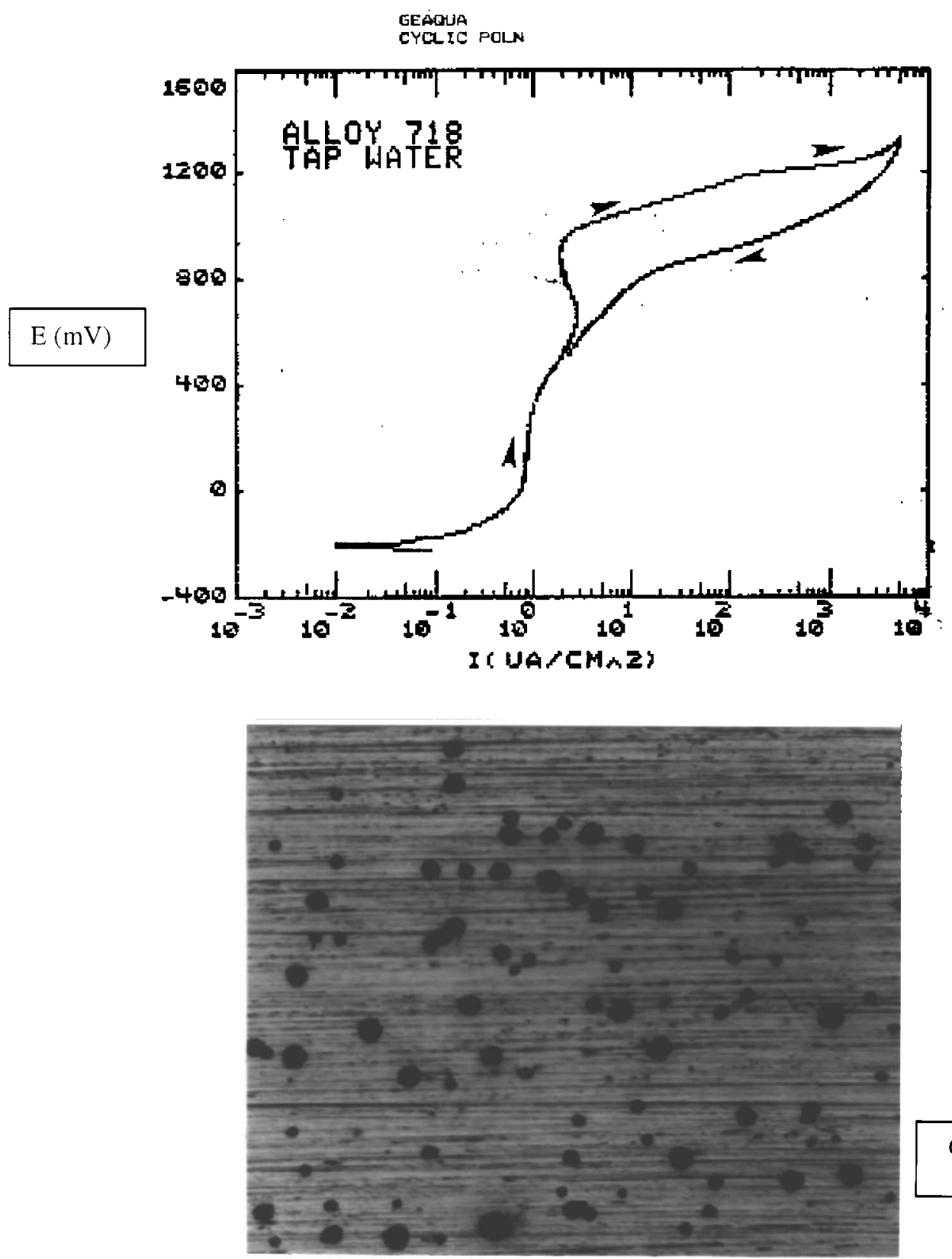

() rigmally $10(0 \mathrm{X}$

Figure 3 Potentiodynamic curves and specimen appearance for 718 in GEAE tap water show positive hysteresis between forward and reverse voltage scans characteristic of a system with potential for local attack. Similar indication of localized attack was obtained in dilute shop fluids. 
Several production process changes were incorporated to combat the observed pitting of production hardware. Once incorporated, intentional corrosion of test material with the production process was no longer feasible. Based on LaQue's results and iterative pitting trials, pitting of finish machined surfaces was accomplished using a $3.5 \% \mathrm{NaCl}$ electrochemical cell at a moderate potential $(3-5 \mathrm{~V})$ against a platinum cathode. Trial pieces of Alloy 718 (Figure 4) confirm that the laboratory corrosion products are similar with respect to residual delta platelets within the corrosion debris.
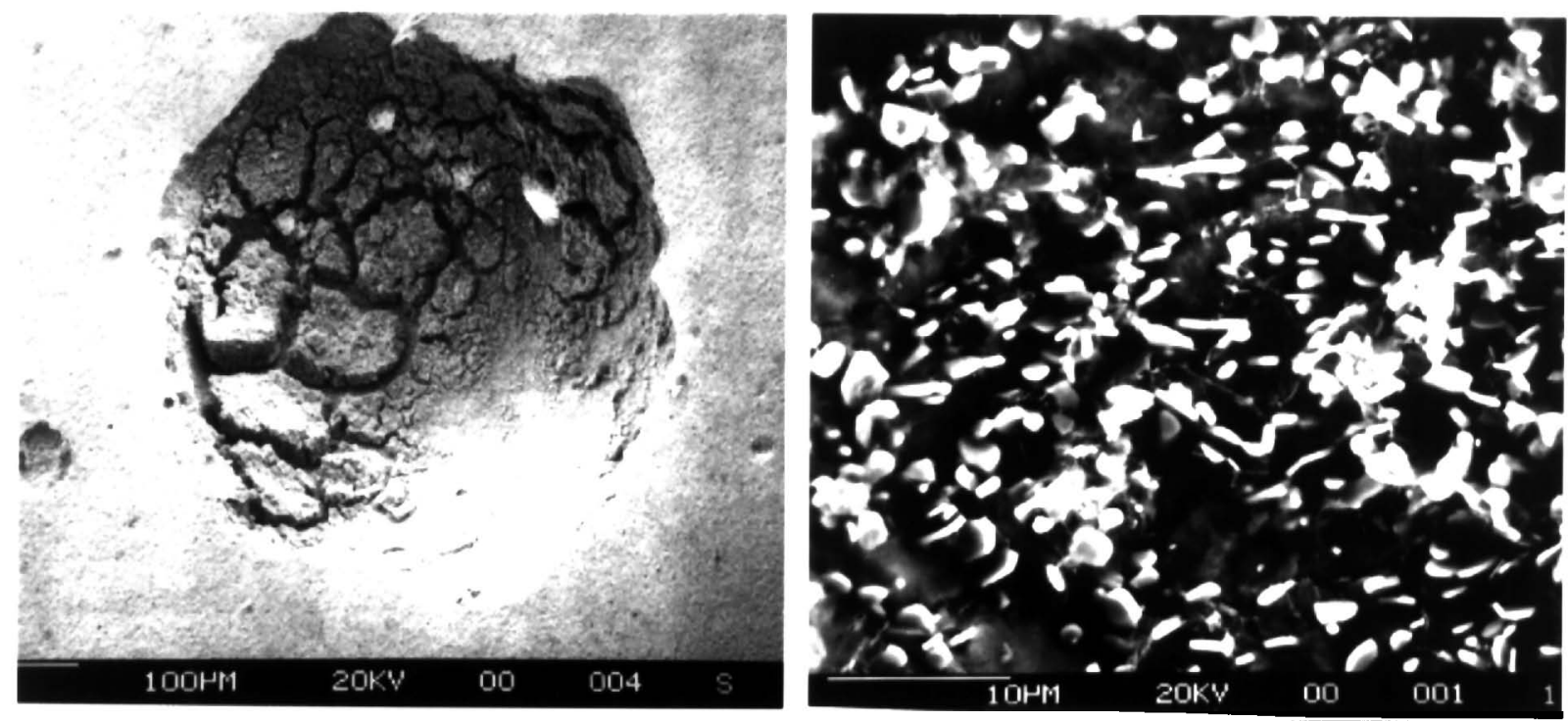

Figure 4 Alloy 718 pitting generated after 15 minutes at $10 \mathrm{~V}$ with a $\mathrm{Pt}$ cathode in $3.5 \% \mathrm{NaCl}+$ water. Delta precipitates were relatively intact; similar to pitting observed on production hardware.

Test bar corrosion pits were formed at a slightly higher temperature $\left(50-65^{\circ} \mathrm{C}\right)$ and lower potential $(3-5 \mathrm{~V})$ to better control pit severity. Test bars corrosion pit showed similar features (Figure 5). Macrographs of bars after test follow in Figure 6.

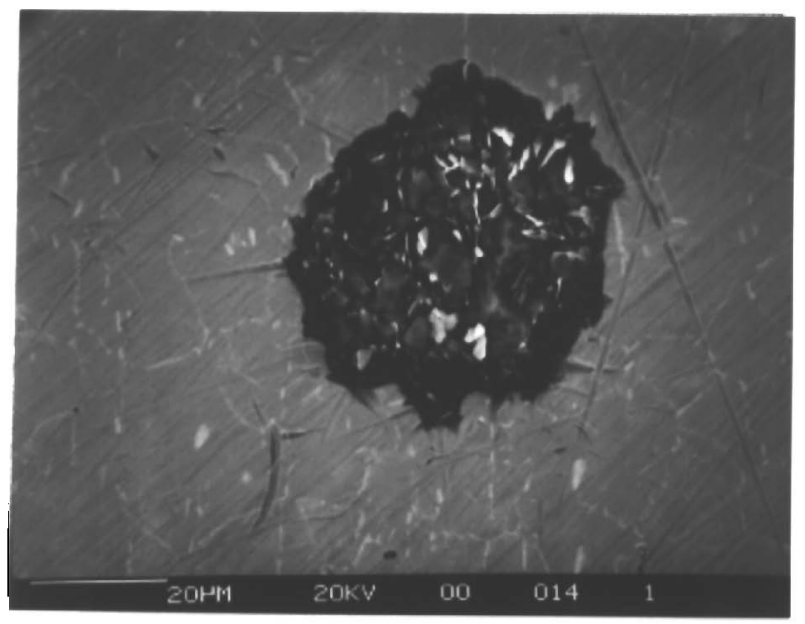

Figure 5 LCF bar pit exhibits morphology and residual delta platelets similar to corroded hardware. 

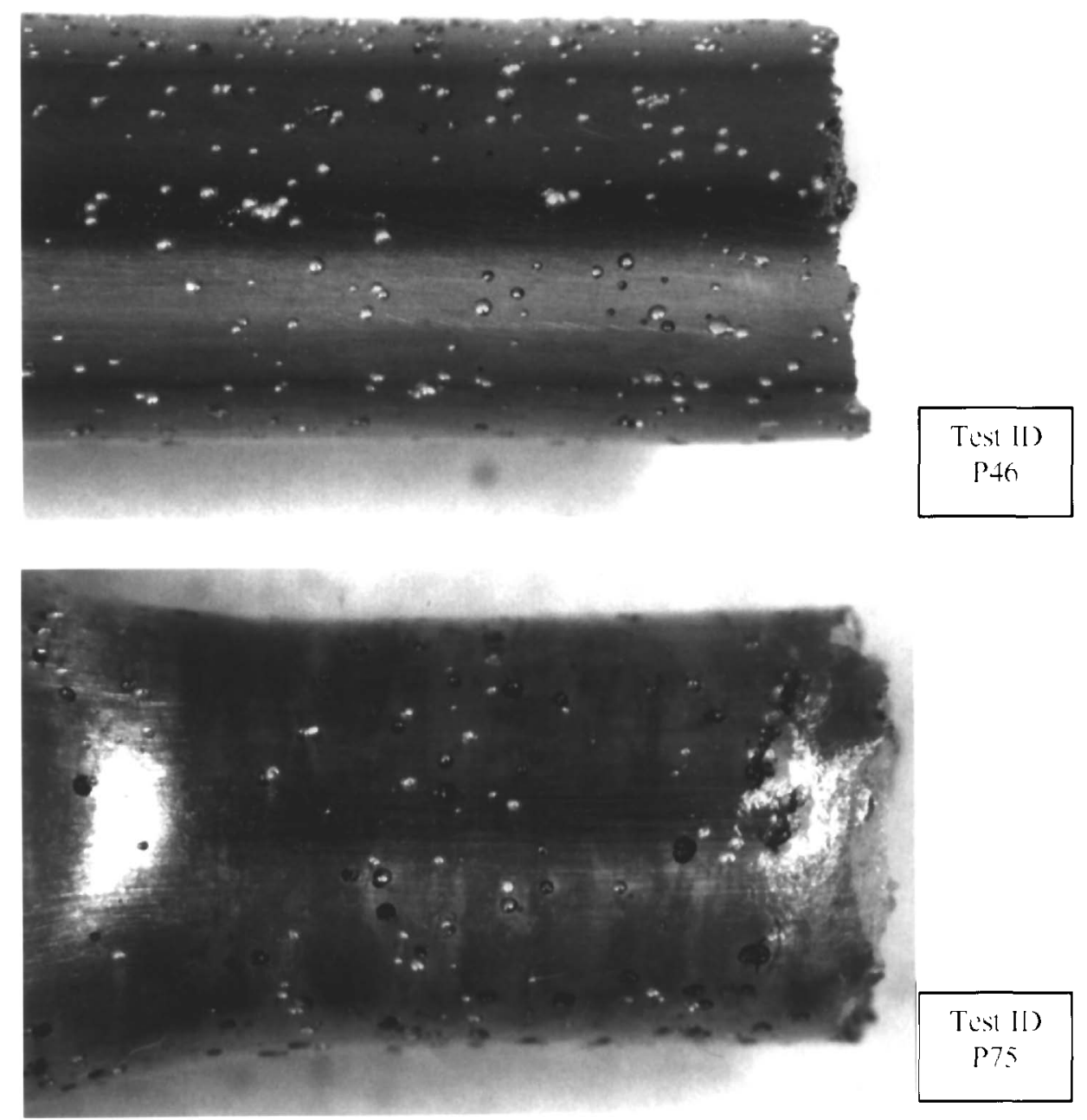

Figure 6 Tested LCF specimens with pits on test gages representing 4 (top) and 7 minutes in $3.5 \% \mathrm{NaCl}+$ water. Longer exposure deepened pits and formed 'furrows' at over-lapping pits.

$6.4 \mathrm{~mm}$ gage diameter

\section{Low Cycle Fatigue Test Data}

Six baseline and eleven pitted bars were cycled at $177^{\circ} \mathrm{C}$ to failure in strain-control. Cycles to failure data and alternating pseudostress, where PsAlt in $\mathrm{MPa}=1 / 2$ (cyclic modulus in MPa*strain), are listed in Table I and plotted in Figure 7. All bars failed within the gage section with numerous pits initiating fatigue on the corroded bars (Figure 8). Baseline tests were within GEAE expectations for this product form. At high strains, a nominal $3 \mathrm{X}$ life reduction was observed while at lower strains the reduction was $\approx 5 \mathrm{X}$. Actual debit varied as a function of PsAlt with a greater disparity at lower test strains. 
Table I

$177^{\circ} \mathrm{C}$ Fatigue Behavior of Pitted Alloy 718

\begin{tabular}{|l|c|c|c|}
\hline $\begin{array}{l}\text { Test } \\
\text { ID }\end{array}$ & $\begin{array}{c}\text { Mid-life PsAlt } \\
(\mathbf{k s i})\end{array}$ & $\begin{array}{c}\text { Cycles to Failure, } \\
\text { Nf }\end{array}$ & $\begin{array}{c}\text { Primary Initiation Sites } \\
\text { Diameter X Depth }(\boldsymbol{\mu m})\end{array}$ \\
\hline B1 & 99.8 & 15,721 & Baseline \\
\hline B2 & 83.5 & 24,964 & Baseline \\
\hline B3 & 83.8 & 43,519 & Baseline \\
\hline B4 & 69.3 & 62,156 & Baseline \\
\hline B5 & 68.8 & 149,346 & Baseline \\
\hline P41 & 97.3 & 4,330 & 406. X 127. X 140. \\
\hline P42 & 78.2 & 13,358 & 812. X 239 \\
\hline P43 & 82.3 & 12,562 & 726 X 127. \\
\hline P44 & 66.6 & 21,867 & $1,016$. X 152. \\
\hline P45 & 66.9 & 17,807 & $1,016$. X 152. \\
\hline P46 & 95.9 & 7,444 & $483 . \times 127 . \& 457$. X 152. \\
\hline P71 & 96.9 & 5,320 & 965. X 178. \& 1,118. X 178. \\
\hline P72 & 79.9 & 8,658 & $2,794$. X 203. Furrow \\
\hline P73 & 81.7 & 7,928 & $1,626$. X 152. Furrow \\
\hline P74 & 69.6 & 14,968 & $1,321$. X 152. Furrow \\
\hline P75 & 67.1 & 18,905 & \\
\hline
\end{tabular}

\section{GFM In718 Bar}

177C, R=.05, strain-control LCF
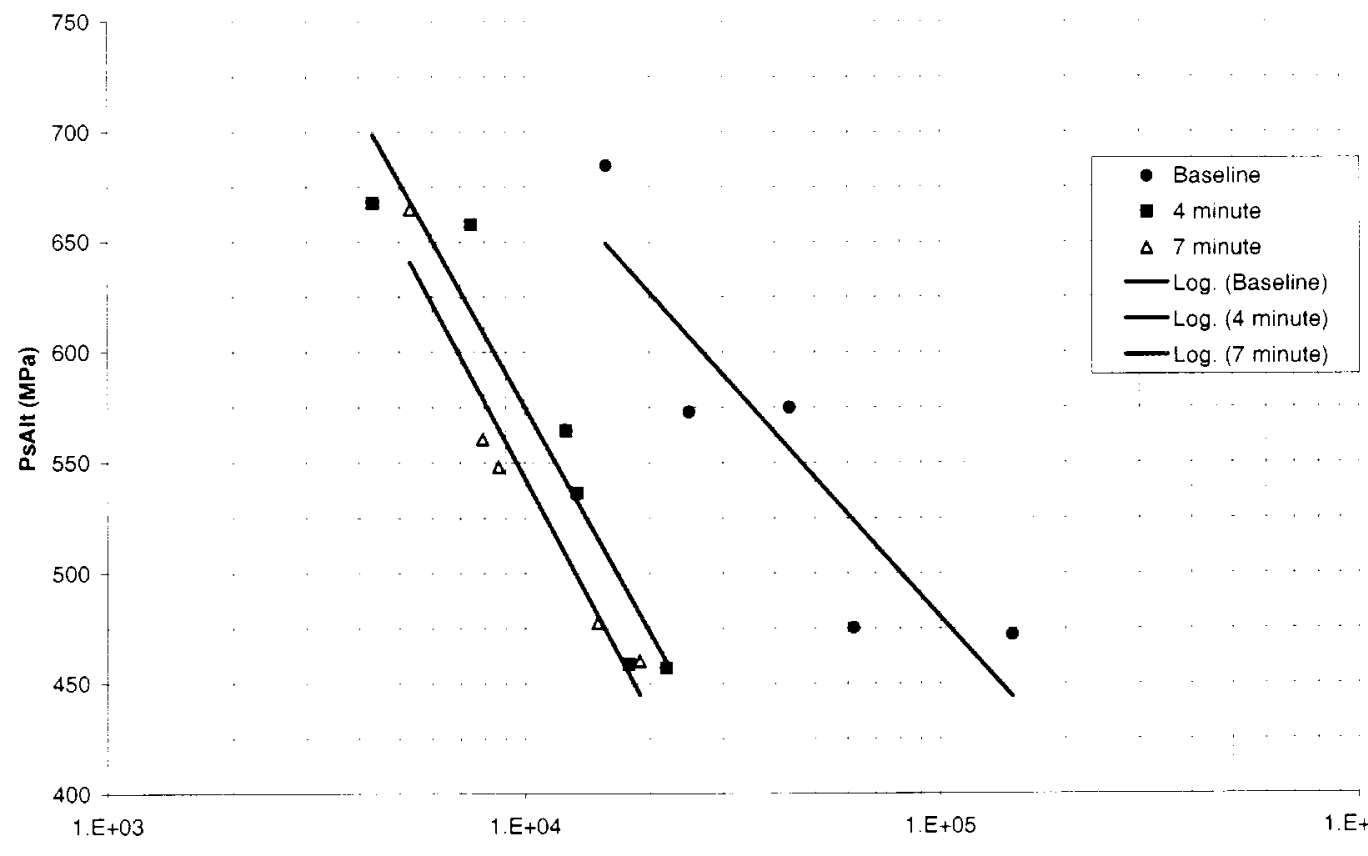

1. $E+03$

$1 . E+04$

1.E+05

1. $E+06$

Figure 7 Low cycle fatigue behavior of baseline and pitted specimens after 4 and 7 minutes in $3.5 \% \mathrm{NaCl}+$ water. Average behavior was reduced $3-5 \mathrm{X}$. 

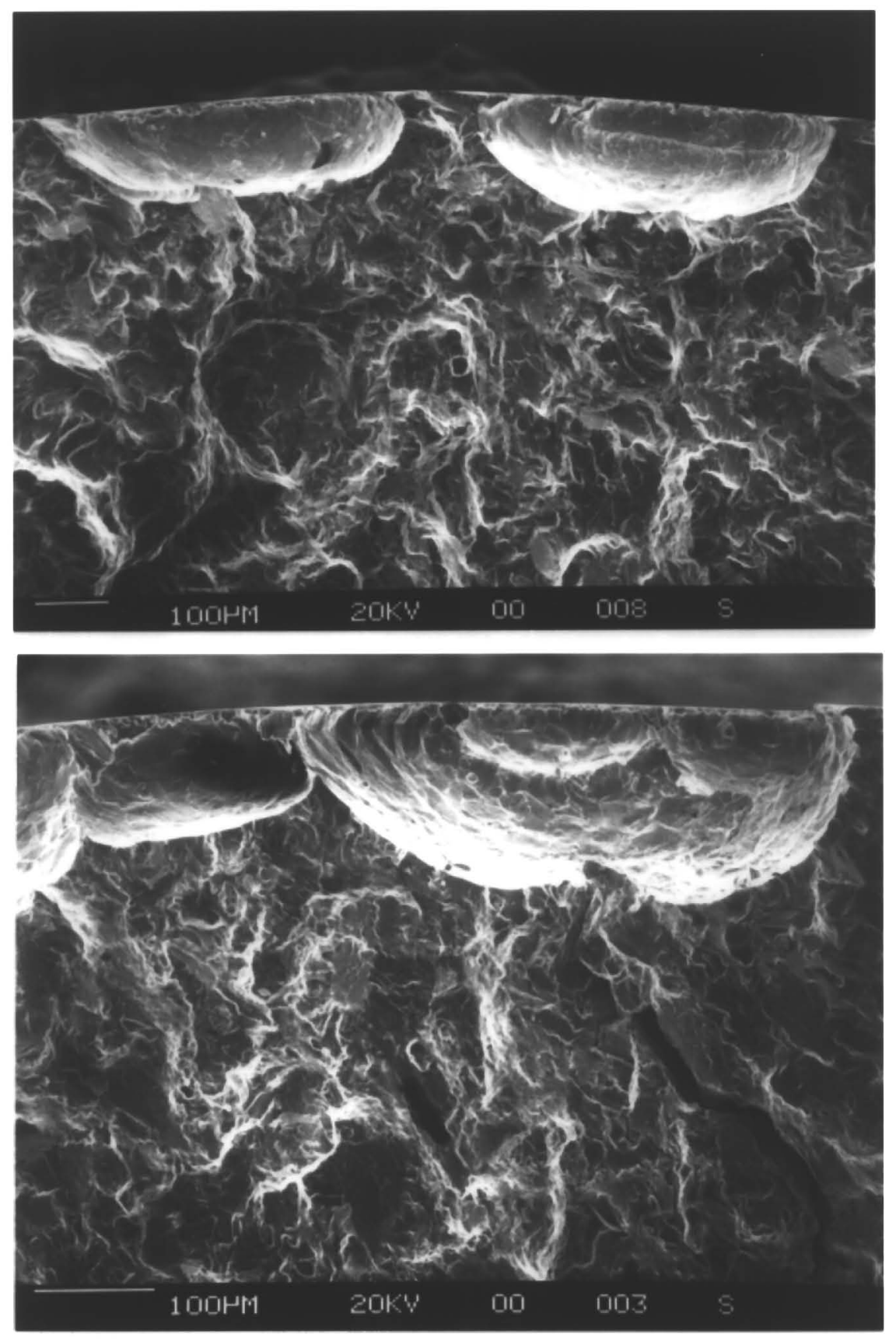

Figure 8 Representative fractographs of fatigue initiation at laboratory-induced pits.

\section{$\underline{\text { Discussion }}$}

Corrosion pit characteristics and fatigue results provided input for Linear Elastic Fracture Mechanics modeling of the corrosion pitting encountered on Alloy 718 hardware. As pitted components were unacceptable for service, the cost of scrap hardware was instrumental in eliminating chromium plating as a wear coating in new part manufacture. Alternate coatings have generally replaced $\mathrm{Cr}$-plate due in part to the rash of corrosion problems. Hexavelent chromium, as found in mist released to the atmosphere as part of 
the plating process, has been reported as a highly hazardous carcinogen ${ }^{7}$. GEAE has carried this chemical on their 'Reduce' chemical list dating to at least 1995, with the expectation that it would eventually be banned. Widespread availability of the Cr-plating process throughout the world has prevented total elimination on GEAE products, but the practice is discouraged.

\section{Conclusions}

Corrosion pits on Alloy 718 rotor hardware surfaces were characterized and simulated to quantify the impact on low cycle fatigue behavior of Alloy 718. The following conclusions are drawn from the present study:

${ }^{1}$ Corrosion pits showed delta platelets in relief, undercut of the part surface, and $\mathrm{Ca}, \mathrm{Cl}$, $\mathrm{K}$, and $\mathrm{Si}$-rich corrosion products within the pit. Delta platelets remain intact within the $\mathrm{Ni}$ - and Fe-rich corrosion residue with intergranular advance on the order of a single grain diameter.

1. Pitting of 718 can be simulated using standard potentio-dynamic polarization tests in solutions containing shop water. A solution of $3.5 \% \mathrm{NaCl}$ and water provided the best controlled method for pitting test bars surfaces in a manner that simulates actual hardware surfaces.

2. Fully-reversed, $177^{\circ} \mathrm{C}$ LCF Alloy 718 data showed a $3-5 \mathrm{X}$ reduction in cycles to failure relative to a non-corroded baseline when tested. Fracture surfaces typically initiate cracking at multiple corrosion pits that behaved similarly to a penny-shaped crack with a surface length equal to the nominal pit diameter.

3. Elimination of $\mathrm{Cr}$-plate process from this and other GEAE hardware virtually removed the occurrence of aqueous corrosion attack on the surfaces of Alloy 718 components.

\section{References}

${ }^{\prime}$ H. Simon and M. Thoma, "Attack on Superalloys by Chemical and Electrolytic Processes", Product Finishing, October 1981, 34-40.

${ }^{2}$ F.G. Hodge, "Effect of Aging on the Anodic Behavior of Ni-Cr-Mo Alloys", CorrosionNACE, 1973, Vol.29, No.10, 181-189.

3 J.R. Groh, "Pitting Corrosion of Alloy 718", internal GE TM\# 92-142, 1992.

${ }^{4}$ G. Kremer and D. Crawford, GEAE Design, Private Conversations, 1992.

${ }^{5}$ Standard Test Method for Conducting Cyclic Potentiodynamic Polarization Measurements for Localized Corrosion Susceptibility of Iron-, Nickel-, or Cobalt-Based Alloys, ASTM G-61.

${ }^{6}$ R.M. Kane "Electrochemical Screening Tests on Alloy 718 in GE Aircraft Engine Production Fluids", Prepared for GEAE by LaQUE Center for Corrosion Technology, 1992.

${ }^{7}$ http://www.epa.gov/region5/news98/980pa279.htm, EPA News release No. 98OPA279. 